\title{
Public interest in the extinction of a species may lead to an increase in donations to a large conservation charity
}

\author{
Christopher F. Clements
}

Received: 30 May 2013/Accepted: 13 July 2013/Published online: 23 July 2013

(C) Springer Science+Business Media Dordrecht 2013

\begin{abstract}
The extinction of a species is an event that often captures the public's imagination. Indeed, declaring a species as extinct is typically though of as a way of raising awareness of the impacts humanity is having on the global biosphere. However, thus far there is little evidence to suggest whether declaring a species as extinct leads to increased public concern, and whether this concern may in turn lead to support to slow future biodiversity loss. To assess this, I look to see whether there is any increase in the number of donations made to a large conservation charity after five recent, well-publicised extinction events that have generated public interest. I find that peaks in public interest in a species that has been reported as extinct may correspond to an increase in the number of donations made, but that other conservation related events may also affect month-month variation in the number of pledges made.
\end{abstract}

Keywords Biodiversity $\cdot$ Conservation funding $\cdot$ Donations $\cdot$ Pledges $\cdot$ Public funding $\cdot$ WWF

\section{Introduction}

Whilst global warming has gained widespread media coverage, the state of biodiversity loss is less well publicised (Novacek 2008; Vaughan 2010). Indeed, recently it has been noted that in general public interest in conservation and biodiversity appears to have been

C. F. Clements $(\bowtie)$

Department of Animal and Plant Sciences, University of Sheffield, Sheffield S10 2TN, UK

e-mail: c.clements@outlook.com; c.clements@shef.ac.uk

C. F. Clements

Institute of Zoology, Zoological Society of London, Regent's Park, London NW1 4RY, UK

C. F. Clements

Institute of Evolutionary Biology and Environmental Studies, The University of Zurich, 8057 Zurich, Switzerland 
waning over the last 10 years (Mccallum and Bury 2013). Media coverage provides a potentially powerful tool to counteract this apathy, as it has been shown to strongly influence public opinion (e.g. Warren 2012). Consequently utilising the media to promote awareness of biodiversity loss should be a primary concern for conservation (Novacek 2008).

News and media interest is driven by sensational stories, significant events, and emotive issues, and in biodiversity terms none fits the bill more profoundly than the extinction of a species. Diamond (1987) suggested that the extinction of a species increases the public awareness of the detrimental effects humanity is having on the environment. Public concern has the potential to directly effect conservation efforts, as many conservation organisations rely heavily on donations (Smith et al. 2012, also see WWF annual report 2012). However, thus far no research has looked at whether there is a relationship between public interest in extinction events, and donations made to charitable organisations.

Here I tackle this issue by looking to see whether public interest, in the form of Internet search effort, translates into an increase in the number of pledges made to a large conservation charity. I select five recent, high profile extinction events and look to see whether: (a) there is an increase in online search activity [strongly correlated with public interest in an issue (Reilly et al. 2012)] associated with the reported extinction of each of these species, and (b) whether there is an increase in the number of pledges made after these extinction events.

\section{Methods}

Data on the number of unsolicited UK pledges per month from April 2005 to March 2013 was provided by the World Wide Fund for Nature (WWF). A donation was considered unsolicited if it could not be traced to any particular fundraising or campaigning activity; such pledges can be considered the "background" level of giving (WWF pers. cors.).

Over this eight-year period there were several well-documented extinction events. I selected five prominent extinctions that showed peaks in Internet search interest after these extinctions were covered by the media, estimated using Google Trends (http://www. google.com/trends) with the species' common name used as a search term. These clear peaks in search interest were required to pinpoint public interest, and identify which data on pledges should be analysed. The extinctions selected were the Yangtze River Dolphin (Lipotes vexillifer) in 2007, the Alaotra Grebe (Tachybaptus rufolavatus) in 2010, the Western Black Rhino (Diceros bicornis longipes) and Eastern Cougar (Puma concolor couguar) in 2011, and the Japanese River Otter (Lutra lutra whiteleyi) in 2012 (IUCN Red List 2013). Google Trends provides data on the frequency of searches made using a given search term, relative to the highest search frequency over the time period of interest, and is regarded as a valid tracker of public curiosity (see Mccallum and Bury 2013 for an in-depth discussion). Global search frequencies of the five species were used, as UK data was unavailable for several of the species. It seems reasonable to assume that global interest in the plight of a species be reflected in the UK population, although the fate of some species (e.g. the Eastern Cougar) may be of more interest locally than globally.

To assess whether public interest in an extinction event led to an increase in donations, I compared the number of donations made in the 3 months prior to a peak in search interest for a species that had recently been declared extinct, to those made in the month of the peak, and subsequent 2 months. The 3-month window of observation was chosen as the longest a peak of search interest lasted was 2 months (the Eastern Cougar), with one 
additional month included for any lag effect associated with giving a donation, or that donation being recorded. I considered a peak to have occurred when the relative search activity reached $100 \%$, however for the Easter Cougar the window of observation was set to include the very high search activity directly before the $100 \%$ activity (Fig. 1).

All calculations were carried out using the $\mathrm{R}$ programming language ( $\mathrm{R}$ Core Team 2013).

\section{Results}

The number of unsolicited donations showed large monthly fluctuations between a maximum of 201 and a minimum of 38 (Fig. 1). Public interest in a species that had been declared extinct was similarly variable, with intense spikes in search activity often followed by sharp declines, the notable exceptions to this being the Yangtze River Dolphin, which exhibited a double peak in interest, and the Eastern Cougar, where there was a relatively high volume of background search interest. The points of maximum search activity appear to often coincide with increases in the number of donations made in a given month (Fig. 1), however there was no significant difference in mean number of unsolicited donations before or after the peak in search interest (paired $t$ test, $\mathrm{t}=2.08$, df $=14$, $p>0.05)$. There was, however, a significant effect of the month on the number of donations made, with the number peaking in June and July (anova, $\mathrm{F}=2.57$, d.f. $=11$, $p<0.01)$.

\section{Discussion}

Typically publicised extinction events are thought to raise the awareness of human impacts on the global biome (Diamond 1987), and though such media attention it is hoped that the current disinterest in biodiversity loss may be reversed (Mccallum and Bury 2013; Novacek 2008). The analysis presented here suggests that public's interest in extinction events is short lived, with intense periods of search activity often followed by little future interest. This is unsurprising, as media coverage of such an event tends to be ephemeral; after the initial declaration of extinction little else is newsworthy. The Easter Cougar and Yangtze River dolphin are notable exceptions to this, with the latter being especially

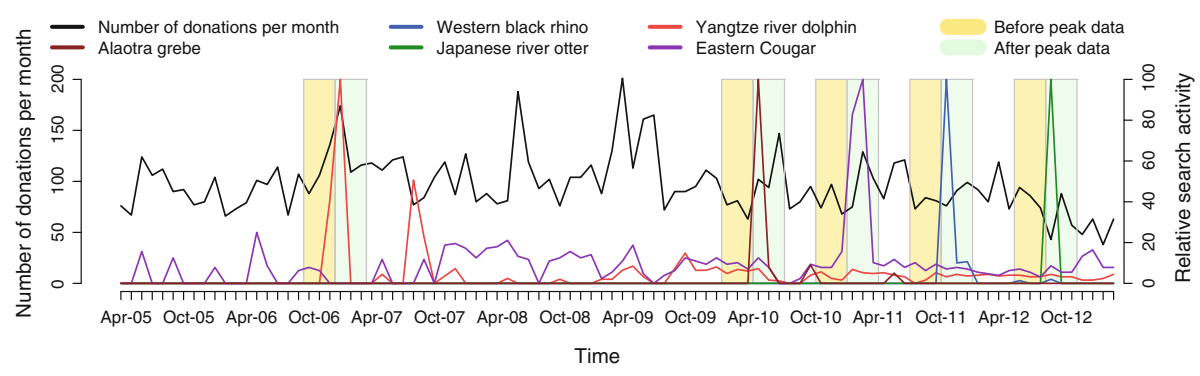

Fig. 1 The number of unsolicited donations per month to the WWF between April 2005 and March 2013, and the relative search frequency of searches for the five species that went extinct over the same period. The mean number of pledges made in the 3 months prior to peaks in public interest were compared to the mean in the following 3 months 
interesting; its search activity shows two clear peaks, one in January 2007, and a second, smaller, in August. This seems likely to be a function of the way this event was reported, with stories emerging in January 2007 saying that a survey in December 2006 had failed to find any surviving dolphins (Turvey et al. 2007), and further articles in August where it was widely declared as extinct (just prior to the publication of the Turvey et al. 2007 paper).

Peaks in public interest over the last 8 years often seem to have coincided with increases in the number of pledges made (Fig. 1), however whether there is a effect of public interest and the number of charitable pledges made remains unclear. The significance of the difference between pre- and post-public interest donations $(p=0.057)$ suggests that there may in fact be an effect, however the small number of extinction events that generated spike sin public interest over the analysed 8-year period (five) is likely to be a determinant of the non-significance.

In some circumstances there are clearly other factors that are driving increases in the number of monthly pledges. Two periods of extremely high numbers of pledges, in June/ July 2008 and 2009, occurred where there were no significant extinction events. Such periods of high funding activity may be attributable to other biodiversity related publicity generated by events like Convention of Biological Diversity (June 2008), where it was widely acknowledged that the 2010 biodiversity targets were likely to be missed (Reuters 2008), the IUCN Shark Specialist Group report (June 2009) that suggested that $32 \%$ of sharks are threatened with extinction (Camhi et al. 2009), or the International Day for Biological Diversity (22 May). Indeed, a post hoc inclusion of peaks in search interest for the International Day for Biological Diversity (using the term "biodiversity day" in Google Trends, which shows yearly peaks around the 22nd of May, and excluding any peaks that overlap with those already analysed above) in the analysis presented meant that there were significantly more donations made after peaks of public search interest (paired $t$ test, $\mathrm{t}=2.54$, df $=23, p<0.05$ ).

It remains clear is that motivating the public to intervene in the current loss of biodiversity is especially important for conservation organisations, as in many cases they derive much of their income from donations made by individuals (indeed in 2012 the WWF received $£ 31.8 \mathrm{~m}, \sim 1 / 2$ of their annual income from donations (WWF annual report 2012). Such pledges are susceptible to the economic climate, and the challenge for conservation organisations is to retain funding even during periods of austerity (Pergams et al. 2004). Extinction events are emotive subjects, especially when the loss of a species can be directly tied to human activity. However, given the short time periods of public interest generated by these events, it would appear critical to harness public support during the 1-2 months where public interest is high, especially if charities are to utilise the loss of a species to secure funding to combat future biodiversity loss.

Acknowledgments I am indebted to the WWF for providing the data analysed here. This research was funded by a Natural Environment Research Council CASE studentship grant (NE/H018700/1) in partnership with the Zoological Society of London. Aaron Thierry provided valuable advice on several versions of this manuscript.

\section{References}

Camhi MD, Valenti SV, Fordham SV et al (2009) The Conservation Status of Pelagic Sharks and Rays: Report of the IUCN Shark Specialist Group Pelagic Shark Red List Workshop. University of Oxford, Newbury 
Diamond JM (1987) Extant unless proven extinct? Or, extinct unless proven extant? Conserv Biol 1:77-79

IUCN Red List (2013) IUCN Red List. http://www.iucnredlist.org. Accessed 28 May 2013

Mccallum ML, Bury GW (2013) Google search patterns suggest declining interest in the environment. Biodivers Conserv. doi:10.1007/s10531-013-0476-6

Novacek MJ (2008) Colloquium paper: engaging the public in biodiversity issues. Proc Natl Acad Sci USA 105(Suppl):11571-11578

Pergams ORW, Czech B, Haney JC, Nyberg D (2004) Linkage of conservation activity to trends in the US economy. Conserv Biol 18:1617-1623

R Core Team (2013) R: A Language and Environment for Statistical Computing. R Foundation for Statistical Computing, Vienna, Austria. http://www.R-project.org/.

Reilly S, Richey S, Taylor JB (2012) Using google search data for state politics research: an empirical validity test using roll-off data. State Politics Policy Q 12:146-159

Reuters (2008) U.N. experts to say 2010 biodiversity target elusive. http://www.reuters.com/article/2008/05/ 16/us-biodiversity-idUSL1628283020080516. Accessed 28 May 2013

Smith RJ, Veríssimo D, Isaac NJB, Jones KE (2012) Identifying Cinderella species: uncovering mammals with conservation flagship appeal. Conserv Lett 5:205-212

Turvey ST, Pitman RL, Taylor BL et al (2007) First human-caused extinction of a cetacean species? Biol Lett 3:537-540

Vaughan A (2010) Public awareness of the biodiversity crisis is virtually non-existent. In: Guardian Environment Blog. http://www.guardian.co.uk/environment/blog/2010/sep/16/public-awareness-biodiversitycrisis. Accessed 28 May 2013

Warren C (2012) Risk and the Sacred: environment, Media and Public Opinion in Bali. Oceania 82:294-307

WWF annual report (2012) WWF-UK's Annual Report and Financial Statements. http://assets.wwf.org.uk/ downloads/annual_report_2012.pdf 